\title{
Beyond Box-Ticking: A Study of Stakeholder Involvement in Social Enterprise Governance
}

\author{
Justin Larner \\ CommEnt CIC, Bolton, UK and \\ Chris Mason \\ Swinburne University of Technology, Melbourne, Australia
}

\begin{abstract}
$\underline{\text { Abstract }}$
Purpose

This paper presents the findings from a small study of social enterprise governance in the United Kingdom, taking a case study approach to uncover the experiences of internal actors who are involved in their board-level management.
\end{abstract}

\section{Design/methodology/approach}

The study took a qualitative constructionist approach, focusing on stakeholder involvement in social enterprise governance. Initial theme analysis of 14 semi-structured interviews with board or senior management representatives revealed key issues in the governance of social enterprise, which were then explored through a comparative case study of two organisations.

\section{Findings}

The study found that social enterprises surveyed employed a number of mechanisms to ensure appropriate stakeholder involvement in their governance, including adopting a participatory democratic structure which involves one or more groups of stakeholders, creation of a nonexecutive advisory group to inform strategic direction and adopting social accounting with external auditing. The research also highlighted the potential of the Community Interest Company legal form for UK social enterprise, particularly in developing the role of the asset-locked body in terms of providing CIC governance oversight.

\section{Research limitations/implications}

This survey was limited to the North West of England; however its findings can potentially support innovation in conceptual developments internationally.

\section{Originality/value}

This research contributes to the under-researched field of social enterprise governance, potentially enabling these organisations to adopt more effective governance mechanisms that appropriately manages the involvement of beneficiaries and other stakeholders.

\section{Keywords}

social enterprise, governance, stakeholder, advisory group, CIC 


\section{Introduction}

Following a recent critical reappraisal of social enterprise (SE), academics have been challenged to provide new directions to contemporary research. Firstly, at the conceptual level researchers are beginning to prise apart the complex (and emergent) relationships between SEs, the state and the private sectors (Curtis 2008, Steyaert and Dey 2010). This is challenging because these relationships are contingent on locale, culture and institutional constraints, with no 'unified definition' of SE (Dacin, Dacin and Matear 2010), creating an on-going debate for all parties, especially practitioners. Secondly, there are increasing calls for more diverse (and qualitative) empirical studies of many aspects of SE, and this naturally supports innovations in conceptual developments (Low 2006, Spear et al 2009). This paper works towards the second goal, presenting the findings from a small study of SE governance in the United Kingdom. As such, we use a case study methodology to uncover the experiences of internal actors who are involved in the board-level management of SES.

Governance in SEs has been defined as 'strategic and operational board-level leadership, enabling service users, managers, trustees and other defined stakeholders to create and maximise social benefit' (Mason 2009, p. 216). This social dimension is an addition to corporate governance, where the role of the board is strategic direction, control of management, reporting to shareholders and meeting the requirements of legislation (Petrovic 2008, p. 1374). Governance is thus clearly key to the success of social enterprise in both business and social terms, however governance 'is a neglected area to date within social enterprise research' (Low 2006, p. 377). This is despite 'new concerns about the quality of governance and accountability of governance and accountability of social enterprises' particularly as they are now seen as more significant in government policy (Spear et al 2009, p. 248).

Stakeholder involvement in social enterprise governance is a particular difficulty faced by these organisations as a 'key challenge for social enterprises is the development and evolution of appropriate governance structures' (Mason et al 2007, p. 289). These need to allow democratic participation as part of civil society (Pearce 2003), however 'implicit to the democratic model is the notion that individual expertise in governance is secondary to a claim to be a representative of a particular stakeholder group' (Low 2006, p. 379). Reconciling these issues could be critical to the success of social enterprise, however 'the evidence base on what are the governance challenges of social enterprises... is very thin' (Spear et al 2009, p. 249).

This research project, undertaken between May and October of 2010, aimed to add to the evidence base for social enterprise governance and identify models of governance that enable these organisations to best fulfil both social and business objectives. The key issues are highlighted through a literature review and semi-structured interviews with a range of social enterprise practitioners, then explored through two case studies. Analysis of the latter leads to a governance arrangement that has the potential to "reconcile" stakeholder involvement and business success.

\section{Stakeholder Involvement in Governance}

Parkinson (2003, p. 495) highlights that the stakeholder approach leads to the 'need for institutions, organisational norms or laws that will ensure that the interests of the various constituencies are reflected in the firm's decision-making'. One such mechanism is to apply 'the principle of reducing the board's autonomy', established in the private sector as being necessary to avoid the interests of directors taking precedence over those of the stakeholders, which can be achieved by organisations having more non-executive directors on their boards (Low and Chinnock 2008, p. 210). However, there could be a potential conflict of interest where non-executive directors have to oversee the executive directors while being part of the same board, in contrast to the German system where a separate supervisory board performs the oversight function (Petrovic 2008, pp. 1385-1386). One possible model of social enterprise governance that overcomes this conflict of interest is offered by 
Mason (2009, pp. 230-232) where an executive board of directors is balanced by an independent stakeholder committee to 'ensure the organisation's accountability' in social audit terms and represent stakeholder interests to the board of directors, with the latter remaining the key decisionmaking body. The staff can be represented on the board, with beneficiaries being represented through the stakeholder committee.

Pearce (2003, p. 117) states that an organisation is not a social enterprise unless it has 'a democratic structure where its constituents may join as members and elect a majority of its board / management committee', however this carries the risk that individuals become Board members 'because of who they represent rather than their ability to manage the assets of the organisation' (Low 2006, p. 379). While acknowledging that an elective democracy can lead to 'bureaucratic and cumbersome structures', Pearce (2003, pp. 67-68) claims that 'structures exist which allow efficient management to coexist with active participatory and democratic structures'.

However there remains the issue that the membership are self selecting and thus not necessarily representative of the organisation's beneficiary group. Cornforth (2004, p. 16) highlights the issue with having 'everyday people' on the board and quotes Block (1998) who advocates a 'cojoint-directorship' model of non-profit governance where the chief executive is seen as a partner of the board rather than subordinate to it, also Davis (1998) who argues that 'senior executives should be part of a co-operative's board and take responsibility for its leadership'. Organisations can try to resolve the dilemma of getting effective democratically elected boards by measures such as seeking to 'improve the quality of members putting themselves forward for election', also by providing training and support for existing and potential board members Cornforth (2004, p. 23). Galera and Borzaga (2009, p. 217) widen the concept of ownership to include a 'single category of stakeholders (users, workers, or donors) or to more than one category at a time'. Thus employeeowned organisations working to the common ownership model, where assets belong to the organisation rather than members (Ridley-Duff 2009, p. 53), could be included in this social enterprise model. These organisations can be governed by a 'workers assembly' that elects a governing body that in turn appoints day to day managers (Ridley-Duff 2009, p. 54), thus ensuring full involvement of the major internal stakeholders in the organisation.

\section{Legitimacy}

Dart (2004, p. 416) after Suchman (1995) sees social enterprises as potentially seeking pragmatic, moral and cognitive legitimacy, which can be defined as (adapted from Dart 2004, pp. 416-417):

1. Pragmatic legitimacy - acceptance by stakeholder groups if an organisation's activities provide them with 'anything of value';

2. Moral legitimacy - alignment with 'broader norms in the socio-political environment';

3. Cognitive legitimacy - the 'taken-for-granted assumptions' that have underpinned the development of social enterprise.

\section{Pragmatic Legitimacy: Social Accounting and Auditing}

Crane and Matten (2007, p. 195) define social accounting as 'the voluntary process concerned with assessing and communicating organisational activities and impacts on social, ethical and environmental issues relevant to stakeholders'. It can be undertaken as an internal organisational process, however independent verification of social accounts, as with financial accounts for the last century, is now being seen as 'crucial', giving assurance to stakeholders that the accounts are valid and a true representation of the organisation's social performance (Pearce 2003, p. 135). Pearce and Kay (2008, p. 22) report, from research into organisations undertaking social accounts, that the majority of funders and investors believe that social accounting 'will eventually become mandatory'. 
Social auditing can contribute to strategic management (Owen et al 2000, p. 85), particularly the Social Return on Investment method (SROI) which uses 'established accounting principles which address any criticism of reliance on anecdotal evidence and the production of non-quantified bottom lines' (Rotheroe and Richards 2007, p. 33). This method of social accounting is now supported by the Government, with the Guide to Social Return on Investment produced by the Cabinet Office (2009, p. 3) to 'help third sector organisations to communicate better their impact to customers' and 'underpin the thinking of commissioners'. At present there is no common reporting standard as with financial reporting, however moves are being made towards one in the UK (Pearce and Kay 2008, p. 32, Nicholls 2007, p. 10) in addition to the global AA1000 Assurance Standard (AccountAbility 2008, p. 6). The SROI method is being promoted for use by investors and grant funders to determine which projects seeking funding will give them the greatest social return for their investment (NEF 2008, p. 11).

\section{Moral Legitimacy:Isomorphism}

Organisations operating in a similar field have a tendency towards isomorphism, or to become more alike, by coercive, mimetic and normative mechanisms (DiMaggio and Powell 1983, pp. 148-150). Social enterprises are particularly vulnerable to isomorphic processes, as they are often established by dynamic individuals who are committed to solving a social problem (Leadbeater 1997, p. 8), however they may not see themselves as social entrepreneurs until recognised as such by support organisations and potential funders (Seanor and Meaton 2008, p. 27). Meyer and Rowan (1977, p. 349) point out that organisations can also experience isomorphism internally as they incorporate 'externally legitimated formal structures' in the process of seeking legitimacy. This process has been identified as 'reflexive isomorphism' by Nicholls (2010, p. 617) where 'dominant organizations can shape the legitimacy of an emergent field' in this case social enterprise, which, according to Chapman et al (2007, p. 78), needs the public sector to 'flourish' and which has been shaped by governments which have put 'faith in market and business-based approaches and solutions' (Dart 2004, p. 418).

\section{Cognitive Legitimacy: Culture and Values}

Dart (2004, p. 421) sees cognitive legitimacy as the basic, preconscious, taken-for-granted assumptions about the nature and structure' of social structures such as organisations, which reflect the culture and values of the society that they are a part of. Deshpandé et al (1993, p. 25) attempted to condense the wide range of potential structures by defining four organisational cultural types that underpin an organisation:

- Clan - cohesiveness, participation, teamwork, sense of family;

- Adhocracy - entrepreneurship, creativity, adaptability;

- Market - competitiveness, goal achievement;

- Hierarchy - order, rules and regulations, uniformity.

Consequently, this assists analysis by providing general, structural templates which can be (roughly) transposed on organisations, thus compared and contrasted. However, this approach neglects the nuances applicable to organisations that value (and are valued) differently. To this end, we follow Cowan and Todorvic (2000, pp. 4-5) and support the view that values are key to the long-term success of any organisation, identifying three 'layers in the value stream':

- Surface values - the obvious activities, behaviours, mission statements etc.;

- Hidden values - the long-standing ideas and beliefs that underpin its work;

- Deep values - the worldview, how reality is defined, by the organisation and individuals within it. 
Deep values form the basis of spiral dynamics, based on the work of Clare Graves, which identifies eight 'zones', or worldviews, each of which could be the dominant worldview of an individual or organisation (Cowan and Todorvic 2000, p. 6). Social enterprise is aligned with the 'green' zone, considering the needs of all stakeholders and working for social benefit, but can suffer its disadvantages, including 'groupthink' and thus could benefit from moving more into the 'yellow' zone, where leadership and principles predominate (Cowan and Todorvic 2000, pp. 8-9).

Social enterprises contribute to building social capital, by creating 'networks, norms and social trust that facilitate co-operation and co-ordination for public benefit' (Putnam 1995, p. 67). Fenton et al (1999, pp. 23-24) point out that trust relates to a situation where there is potential for damage to an individual, where 'personal feelings of faith and hope' are involved. However, 'for values-based organisations trust is a critical issue', attempts to be more accountable and communicate with beneficiaries lead to them being seen as being too business-like which can cause a loss of trust. This is a particular issue for social enterprises, which are driven by their values and the needs of their beneficiary community but also seek to be run as a business.

\section{Leadership and Group Dynamics}

An organisation needs to be clear about who has the authority to carry out its work, where 'authority refers to the right to make an ultimate decision, and in an organisation it refers to the right to make decisions which are binding on others' (Obholzer 1994, p. 39).

Authority can be from three sources (adapted from Obholzer 1994, pp. 39-42):

- Authority from above - formal authority gained by undertaking a role within an organisation, such as that of a director who has authority from the board, who in turn gains its authority from the shareholders or members. Such a hierarchy can be complicated by stakeholders in a voluntary sector organisation who 'may all, in different ways, claim ownership of the organisation'.

- Authority from below - the authority granted from above also needs to be accepted by those over whom the authority may be exercised. If there has not been enough dialogue with the latter, there may be 'undermining and sabotage'.

- Authority from within - this refers to the individual's own view of their authority and can range from doubt as to if they can fulfil the role to 'omnipotent' authoritarian attitudes.

Authority must be balanced by power to be exerted effectively, however the common job title of 'coordinator' implies that 'there is very little power and capacity to exert sanctions' (Obholzer 1994, p. 42). Both authority and power need to be matched by responsibility for outcomes, however responsibility without power or authority can lead to burn-out (Obholzer 1994, p. 43). From a business perspective Drucker (2007, p. 18) states that the 'customer defines the business', however from a social enterprise perspective it is more useful to think in terms of the 'primary task' which the organisation 'must perform if it is to survive', which can be divided into (Roberts 1994A, p. 30):

- Normative primary task - the official task of the organisation;

- Existential primary task - the task people within the organisation think they are undertaking;

- Phenomenal primary task - that task that is not consciously articulated can be inferred from behaviour.

The latter can arise from individuals who, due to unresolved issues from their past, set themselves an unconscious 'self defined impossible task', several such individuals can influence a work group to the extent that the whole group adopts this mentality, which 'serves as a defence against the 
difficulty and stress of working at the possible' (Roberts 1994B, pp. 112-115). Drawing on the work of Bion, Stokes (1994, p. 20), identified that where the work being undertaken by a group 'is painful or causes psychological conflict within or between group members', particularly when working in health or social care, the group can retreat into 'basic assumption mentality', where the three basic assumptions are (adapted from Stokes 1994, pp. 21-23):

- Dependency - where a group behaves as if its sole purpose is to fulfil the needs of its members rather than those of the organisation.

- Fight-flight - where the group substitutes worrying or protesting about an external danger for dealing with either it or the group's work.

- Pairing - where the group behaves as if 'pairing or coupling between two members of the group, or perhaps between the leader of the group and some external person, will bring about salvation' from present difficulties, thus avoiding decision-making.

This synthesis of governance, leadership and group dynamics leads to a central research question:

RQ: What are the mechanisms that most effectively allow stakeholder involvement in the governance of social enterprise?

As we have noted, this is a nascent but still under-researched field which offers a wide spectrum of opportunities for SE researchers. We have adopted a combinatory approach which recognises the duality of individual (agency) perspectives contrasted within meso-level organisational "structures" such as boards and the process of governance. This leads us to examine the research problem in two stages; firstly to establish what the key issues were and the second to explore the defined issues in greater depth through two case study organisations.

\section{$\underline{\text { Methodology }}$}

The study of stakeholder involvement in organisations is undertaken from a phenomenological perspective, taking a constructivist approach to 'stakeholder evaluation' (Vartiainen 2003, p. 10), recognising that the research can contribute to the development of social enterprise in a 'coproductive relationship' (Steyaert and Dey 2010 p. 232). This perspective leads to qualitative methods, which can 'access aspects of organisational realities that would otherwise be missed' (Cassel et al (2005, p. 14). Specifically, research into stakeholders of organisations will best be developed as a dialogue process that enables learning by both researcher and subjects (Vartiainen 2003). This can be achieved through the process of mimesis, where experience is transformed into texts, interpreted, then these interpretations are 'fed back into everyday contexts' (Flick 2009, pp. 78-79) to become part of the organisation’s learning process (Kolb and Kolb 2005, p. 194).

\section{Semi-structured interviews}

The interview was chosen as a method that can 'explore a central research question' (Broom 2005, p. 67), in this case to identify the issues with stakeholder involvement experienced by people directing and managing social enterprises. A purposive sampling approach (Patton 2002, p. 230) was used to find 14 organisations, mainly operating in the North West of England, with at least two in each of Spear's (2009) categories:

- Mutual organisations;

- Trading charities;

- Public-sector spin-offs;

- New-start social enterprises. 
A summary of the issues highlighted in the literature review formed the basis for semi-structured interviews with the Chair or CEO of these organisations in North-West England in June and July 2010. The interviews were digitally recorded and the recordings analysed using QSR NVivo 8. This process started with a summary transcript that was approved by the interviewee, which was then "coded" by tagging with key words, or "nodes". By the end of the process of coding the interviews, no new nodes were emerging, indicating that the sample size was large enough to be approaching 'redundancy' (Patton 2002, p. 246). Grouping these key words under relevant “tree nodes” enabled the linked text to be extracted and edited to create an Interim Report that was sent to all participants for comments and further thoughts, involving them in triangulation through participant review (Patton 2002, p. 560).

\section{Issues Raised}

The main issues raised at this stage were:

1) Ownership of a social enterprise

A key dilemma for the organisations surveyed was where ultimate power should be vested, in the directors or the stakeholders. Many organisations manage this ownership through a voting membership who have ultimate power, including being able to replace the Board or the founders of the organisation. A voting membership can thus be disruptive, but can also be seen as an essential democratic representation of stakeholder interests, enabling true community ownership. However, others saw their organisation as a social business, operating as a private company with a social mission and owned by its directors or other shareholders.

2) Should executive or non-executive directors be in the majority and should the latter be paid?

The organisations surveyed drew on both private and voluntary sector practice to deal with this issue, balancing executive directors who are responsible for day to day decision making with non executive directors who are responsible for the overall vision and strategy, acting as checks and balances, dealing with complaints against the executive directors and deciding on remuneration. Non executive directors were generally unpaid.

3) The nature of stakeholder involvement, is this through consultation or direct voting rights?

A major issue for the organisations surveyed is conflict amongs the various stakeholder interests in the organisation, particularly where the power balance lies. Mechanisms to facilitate stakeholder involvement included:

- The membership voting non executive directors onto the Board, with the power of these non executive directors can ranging from being in the majority and able to outvote the executive directors, to having a non-voting advisory role.

- Creating an Advisory Group which can represent stakeholder interests to the Board, enabling consultation of stakeholders who may be vulnerable or who do not wish to have any responsibility for running the organisation.

- Having a cooperative structure, which included employee co-ops and community co-ops, particularly in terms of capacity building individuals so they can become involved in the design and management of services or even create their own worker's co-op.

\section{4) Legitimacy, how can a social enterprise demonstrate that it is fulfilling its social purpose?}

The organisations surveyed emphasised the importance of values, maintaining and expressing them 
in the work of the organisation. They employed a number of mechanisms to demonstrate that they were legitimately fulfilling a social purpose:

- Consultation with stakeholders on a day to day basis, ensuring that their views are acted upon.

- Evaluation, this can enable engagement with stakeholders as well as verifying social benefit.

- Social accounting and audit, using a range of methods including Social Return on Investment, Contingent Value Method, Social Impact Tracker and those offered by the Social Audit Network. There are difficulties with social accounting, particularly equating a financial value with social benefit. The accounting process can be built into the organisation's governance, putting social accountability putting social accountability at the heart of the organisation.

- Asset lock, which protects assets on behalf of the beneficiaries even if the organisation closes down.

5) How can effective and timely decision-making be reconciled with representation of stakeholder interests?

Interview participants indicated that governance of a social enterprise often gets taken for granted without enough thought being given to it either before the organisation is set up or while it is in operation. Many organisations seem to struggle with finding workable mechanisms for appropriate stakeholder involvement, with key issues including:

- The board needs to have the power to run the organisation.

- There is a trade-off between having a Board that makes quick decisions and one that takes into account representation of stakeholder interests.

- The amount of responsibility stakeholders should have for the running of the organisation.

- The distinction between strategic and operational decision-making.

- The competence of directors, particularly if they are volunteers.

- Election of board members from a voting membership leaving an organisation vulnerable to takeover.

6) Should staff be on the board and in what role?

This issue was another dilemma for the organisations surveyed, as having senior staff members as executive directors can ensure timely and competent operational decision making, however fears were expressed that the staff could end up running the organisation in their owninterests.

7) The impact of new technology, will it change the nature of governance and stakeholder involvement?

The use of new technology, particularly the Internet, social networking and "open source" techniques, is changing how social enterprises communicate with both internal and external stakeholders, potentially allowing greater involvement in decision-making.

8) Which legal form is most appropriate for social enterprise, or should a combination of them be used?

Legal forms adopted by the organisations surveyed included:

- Registered Charity, governed by Trustees, who take on potentially onerous personal liabilities despite being volunteers. This can lead to major governance problems as trustees 
need to be risk averse which is incompatible with trading unless a subsidiary is used. However, having charitable status can enable getting grant funding as the organisation is seen as legitimate by funders, but this combined with the difficulty of trading leaves the organisation dependent on grants and donations.

- Company Limited by Guarantee, which are generally set up with volunteer directors, raising issues about the time they can give to the organisation and the difficulty of recruiting competent directors as volunteers.

- Company Limited by Shares, this appears to be the only legal form that is attractive to mainstream private investment, as they will not invest in an organisation with asset lock.

- Community Interest Company, CICs can be limited by guarantee or by shares, with an asset lock and mandatory reporting to the CIC regulator ensuring that organisations that adopt this form demonstrate some accountability. However, the asset lock means that intellectual property is also locked in, which is a problem for individuals who have invested in creating it.

- Industrial and Provident Society (or Bencom), this form is seen as more democratic than other legal structures, with a voting membership as well as a lock on assets, however the voting membership may cause difficulties for an organisation in terms of resources and possible takeover if the membership can vote for the Board. Elaborate governance structures locked into the governing document can overcome this, however.

- Some organisations are now using a combination of legal forms, often linked by profit sharing arrangements. This leads to more overheads in terms of management time, however.

\section{Case Studies}

A case study approach is appropriate to investigate a 'phenomenon in depth', where 'the boundaries between phenomenon and context are not clearly evident' (Yin 2009, p. 18). In this project, the case study approach can fulfil the objective of reviewing in depth the issues with, and potential mechanisms for, stakeholder involvement identified in the semi-structured interviews. The starting point for a case study is one or more 'theoretical propositions' (Yin 2009, p. 130), which are an 'essential step' which distinguishes the case study approach from ethnography and grounded theory (Yin 2009, pp. 35-36). When the organisations surveyed were sent the Interim Report, they were also asked which issues were particularly significant to them and if they were interested in participating in a case study to explore these issues further, thus involving them in the case study design.

The Interim Report formed the basis for these propositions:

1. A social enterprise enables its stakeholders to exert ultimate power over the organisation through a democratic process;

2. A social enterprise demonstrates its legitimacy through verifiable evaluation against its social aims;

3. A social enterprise ensures that stakeholder interests contribute to its decision-making processes.

The two case study organisations were chosen from those previously interviewed using a form of the 'most similar' technique (Seawright and Gerring 2008, pp. 304-305), where they are similar except the variable of interest, in this case governance.

The data gathered included organisational documents and an additional interview with another representative of senior management, taking a participative approach. This approach links with action research, where it is acknowledged that even reflecting and discussing social phenomena inevitably changes them and research into 'social reality' needs to be 'a collaborative process' 
enabling 'reflective learning' (Checkland and Holwell 1998, p. 12). This part of the research draws on ethnographic techniques (Flick 2009, p. 169) to allow greater involvement by the researcher, potentially leading to a deeper understanding of its culture, including the 'basic assumptions' (Stokes 1994, pp. 21-23), 'rhetoric and "reality"' (Watson 1995, p. 807) and the 'deep structures of activities... not accessible to everyday individual reflections' (Flick 2009, p. 62). This process was further facilitated by taking handwritten notes during the interview as part of a more reflective approach where both interviewer and interviewee learn from the process (DiCicco-Bloom and Crabtree 2006, p. 315). This write-up was sent back to the participants for checking and to allow any further reflections on their part to be added.

The case study data were then analysed with NVivo, following a similar technique to that used for the semi-structured interviews. The text under each tree node was extracted from NVivo and edited through a reflective process that drew on the techniques of phenomenological analysis, which aims to 'grasp and elucidate the meaning, structure and essence of the lived experience of a phenomenon' (Patton 2002, p. 482). The process of content analysis and 'and sense-making effort' (Patton 2002, p. 453) contributes to the creation of rich description that allows the reader to draw their 'own interpretations about meanings and significance' (Patton 2002, p. 438). The descriptions of the two case study organisations are summarised below.

\section{$\underline{\text { Results }}$}

\section{Organisation A}

'The development of the organisation wasn't driven by the Trustees, this is something that happened organically... if you can get well motivated, enthusiastic and capable people who are also

beneficiaries that's a good thing for the organisation.'

Organisation A aims to help people with a particular long term physical health condition 'to lead fuller lives' through providing training, employment opportunities and specialised treatment, creating an environment where 'disability is no barrier to achievement'. A is a subsidiary of a national organisation working in the same field that is its sole trustee and director, however it works autonomously from its parent, helped by it having moved frombeing a 'burden' in the past to its current 'cash cow' status, where the value of A's work is recognised as complementing that of its parent. A has moved from being totally reliant on grant funding to only receiving $60 \%$ of its income from grants, the rest from trading and fundraising income.

While being ultimately managed by its parent organisation, oversight of its day to day management is delegated to a Consultative and Advisory Group. This group includes service users, staff who are also service users and other individuals with an interest in the organisation. The group acts as a reference when decisions are taken about matters such as staff salaries and provides a 'challenge' that is welcomed by staff, keeping the latter focused on the purpose of their work. Staff provide support to service users to enable them to be fully involved in the Advisory Group. This support contributes to an organisational culture of 'unspoken democracy' where staff and service users can feel that they own the organisation and the staff feel that their authority as 'coming from the service users here', that they are working on their behalf. This culture has developed over the years and is 'absorbed by ESP' by those who 'get it'. However, there are concerns that it could be a bit too 'cosy' and about service users being dependent on the organisation. A is considering a paid membership scheme to promote greater involvement in the organisation.

A considers its stakeholders to be service users, their families and carers, also health professionals, staff, volunteers customers, funders and donors. A undertakes a full social accounting and auditing process involving stakeholders through evaluation processes including surveys of service users and 
carers, consultation with staff and clinical peer review. The organisation is taking care to avoid 'survey fatigue', however, by not evaluating every aspect of its work every year but over a 3 year period.

A is now seeking to 'transplant' their culture into other areas by establishing a network of similar but independent organisations that would belong to their community with 'local ownership'. The organisation is also seeking to become independent of its parent charity. Independence would enable the present Advisory Group to become a Board of Trustees, with the paid membership potentially electing a new Advisory Group.

\section{Organisation $B$}

'We're very clear this is a social enterprise: we have as much in common with the public or private sectors as we do with the so-called third sector. Some people call themselves social enterprises when they're not, probably the majority. I think we can genuinely say we are: this is a business that trades for a social purpose.'

Organisation B aims to provide health and well-being services for NHS and local government customers that make a real difference to people's lives by 'thinking creatively, being innovative', reaching people that statutory services were not able to. B is financially prudent and makes it clear to customers that they are 'a social enterprise, not a grant dependent voluntary organisation', with the customers now 'taking us seriously as a long-term business partner'. B aims to make a surplus 'with no strings attached' to be re-invested in new services at its discretion.

B is now an Industrial and Provident Society, wishing to 'embed members in how the organisation was run', with its values and principles 'built into the DNA of the organisation'. These values include being approachable and having respect for feelings or rights. The constitution was set up to not only lock in the assets, but 'the mission, the values, the objectives, the whole nature of it being for the benefit of the community, in a way that is virtually impossible to undo and privatise'.

The organisation works to a 'triple bottom line' of social, economic and environmental benefit, with this benefit being 'business marketing material' where customers can gain not only the service purchased but also 'social, economic and environmental value on top' including knowing that their investment in the organisation will create local jobs and extra social benefit from re-investment of surplus.

Any person with an interest in the organisation can become a member, who are divided into three groups, clients, staff and anyone else. The membership has the ultimate ownership of the organisation, including 'the power to appoint and remove the Board'. As well as the elected nonexecutive directors, the Board has a Chief Executive and two other executive directors who are appointed by the Board. Both these other executive directors report to the Chief Executive, which potentially creates a hierarchy in the Board, however the executive members of the Board work together to present a united viewpoint to the full Board. B also created an Advisory Council which is elected from the membership, making a 'conscious decision' to give it 'real teeth' to act as the organisation's 'conscience', including calling a meeting of the full membership, ensuring that it does the right thing for its community. B acknowledges that they need to do a 'huge amount of work to get clients involved', particularly in the Advisory Council.

B identifies its key stakeholders as customers, clients, staff, volunteers, members and directors. Other stakeholders include local communities, investors, suppliers and regulatory bodies. These stakeholders are consulted using a range of methods as part of a comprehensive social accounting process, including online surveys, postal questionnaires, focus groups and the 'Balance' tool for 
Board evaluation, to the point where concern is expressed about not overloading clients 'with too many surveys and questionnaires'. Social accounting is now 'embedded in the organisation' from Board level downwards through all the policies and procedures.

\section{$\underline{\text { Analysis and Implications }}$}

The following summary of the research findings considers the case study evidence against the theoretical propositions.

\section{P1: A social enterprise enables its stakeholders to exert ultimate power over the organisation through a democratic process}

This proposition is partly supported:

- One case study organisation has a formal governance structure which explicitly gives ultimate power to its stakeholders to join as members and then elect or remove the Board of Directors. This organisation also has a non-executive advisory body which is also elected from the membership which functions as a mechanism for alerting the membership to problems or issues with governance. However it is experiencing difficulty in recruiting a membership from clients and the general public, meaning that it is currently owned by existing non-executive directors and staff members.

- The other case study organisation wishes to increase the power of their stakeholders by creating a Trustee Board when it achieves independence, but this would not be elected from a voting membership. They are also considering having a paid membership which could elect a new Advisory Group to complement the Board of Trustees but this would not have any formal ownership of the organisation.

The literature partly supports this proposition, with Pearce (2003, p. 117) claiming that a membership that elects the majority of the governing bodyis necessary for an organisation to be a social enterprise, also that the potential problems this could cause can be overcome by being clear about the roles of board and management (Pearce 2003, pp. 67-68). However, this does not overcome the problem of the membership being self selecting and thus not necessarily representative of the organisation's stakeholders. Galera and Borzaga (2009, p. 217) offer a wider perspective on ownership, which can be by a single group of stakeholders, such as workers or clients or by multiple groups. The concept of an advisory group is endorsed by Mason (2009, p. 232) who proposes an independent stakeholder committee to complement the executive board of directors. This independence is supported by Petrovic (2008) who points out the potential conflict of interest in non-executive board members having the role of overseeing the executive members while being part of the same board.

\section{P2: A social enterprise demonstrates its legitimacy through a verifiable evaluation process against its social aims}

This proposition is supported by the case study evidence, as both organisations undertake a full social accounting process with independent auditing. Organisation B takes social accounting a stage further, building its framework into their governance and organisational procedures. The case study organisations also identified additional mechanisms that demonstrated legitimacy:

- Additional consultation to ensure that the best possible service is being provided to their beneficiaries, however, both case study organisations expressed concern about overconsultation of service users.

- An organisational culture where stakeholders can feel both welcome in and have informal 
ownership of the organisation.

- Being a values driven organisation.

- Having assets locked in for the benefit of the community.

The literature supports this proposition, with social accounting and auditing being seen as being key in demonstrating to stakeholders the organisation's social performance (Pearce 2003, p. 135), thus encouraging involvement by stakeholders in an organisation they see as credible. However, the trend towards mandatory social accounts could move this pragmatic legitimacy towards moral legitimacy (Dart 2004, pp. 416-417), as a process of 'reflexive isomorphism' (Nicholls 2010, p. 617), where the organisation can end up being shaped by the requirements of these dominant influences, rather than the community which inspired its formation. Considering cognitive legitimacy in terms of cultural types, (Deshpandé et al 1993, p. 26), each case study organisation shows a distinct approach:

- A is more orientated towards organic processes, characterised by a sense of family where clients feel at ease in the organisation, that it is theirs. The organisation is taking an entrepreneurial approach to moving into other areas, again through an organic process that has been likened to propagation.

- B is more orientated towards mechanistic processes, with a complex hierarchical governance structure and emphasis on building in social accounting into all its policies and procedures. Its external positioning is also on this side of the model, with a stated aim of providing a competitive service that offers additional social value, hence gaining market superiority.

\section{P3: A social enterprise ensures that stakeholder interests contribute to its decision-making processes}

This proposition is supported, as the case study organisations allow stakeholder interests to contribute to decision-making via different mechanisms:

- Stakeholders joining as members then being elected to non-executive positions on its governing body and to its advisory group.

- A non-executive management advisory board with inyolvement from a range of stakeholders including clients and staff.

This proposition is further supported by considering values and culture, the 'deep values' of the case study organisations are in the 'green zone', characterised by a worldview that emphasises involvement of all the people who might be affected in the management of the organisation and a sense of social responsibility, with Organisation B also showing elements of blue', with increasing formalisation of procedures (Cowan and Todorvic 2000, pp. 7-8).

The literature supports this proposition, with Thompson and Doherty (2006, p. 362) claiming that one characteristic of a social enterprise is that members or employees contribute to decision making, the latter particularly if they are from the community the organisation serves (Mason et al 2007, p. 290). Involvement of stakeholders can be key to building social capital by building trust, potentially preventing the loss of trust that can accompany community based organisations being seen as becoming too professional as they develop (Fenton et al 1999, pp. 23-24).

\section{Conclusions and Recommendations}

Although this survey was a relatively limited one of organisations that considered themselves to be social enterprises in the North West of England, some conclusions can be drawn that could be more widely applicable. The research found that the most effective mechanisms for stakeholder 
involvement in social enterprises were:

\section{Worker-directors in a cooperative model}

Direct involvement of the key stakeholder groups of workers or beneficiaries, ideally when these are the same individuals, as directors of the organisation. This cooperative model, where the governing body is formed from the workers or representatives of the workers, particularly when the same individuals are also the beneficiaries, gives this group of key stakeholders ultimate power in a participative democratic structure. This arrangement also ensures that the individuals in the organisation's governing body have the responsibility for decision-making but also the power to carry them out effectively. Having a self-selecting voting membership in an elective democratic structure seems less effective, however, as decision-making can be slowed down or the organisation disrupted.

\section{Stakeholder advisory group}

Stakeholder involvement in governance can be achieved by complementing the board of directors with a stakeholder advisory group that is non-executive but plays a key role in monitoring the organisation's work and contributing to strategic development. This can be a useful mechanism for involving stakeholders, particularly beneficiaries, in governance without burdening them with a legal responsibility towards the organisation that being part of a voting membership would entail. It could thus be particularly effective when the beneficiaries are not in a position to take on responsibility due to health or other commitments. The advisory group could be elected from the organisation's wider membership, complementing a participatory board of directors, thus helping to overcome any tendency for the executive board to become too inward looking. In an organisation working to a cooperative model, the advisory group can contribute to fulfilling the functions that non-executive directors undertake in a limited company, of strategic oversight and dealing with conflicts of interest, such as with remuneration. However, finding individuals to participate in the group may be a problem if they see little immediate personal benefit.

\section{Social accounting and auditing}

Social accounting and auditing proves an effective means for an organisation to demonstrate social value in return for financial investment and maintain the legitimacy of its social aims. The process potentially encourages stakeholder involvement in decision-making and gives the directors of the organisation clear direction and thus authority to carry out work that is for social benefit.

\section{Values and culture}

The organisation creating a culture where values, rooted in the needs of the beneficiary community, drive the organisation through its governance, management and everyday work. This culture, however, is in danger of being lost as the enterprise develops and is subject to isomorphic pressures such as requirements from funders and social accounting methods to demonstrate formal systems of accountability to stakeholders. This issue highlights the importance of a values based organisational culture and clear leadership.

\section{Implementation}

The recommendations from this research could be implemented in the UK by adopting the Community Interest Company legal form and extending the role of the asset locked body:

- The CIC form confirms legitimacy as a social enterprise, as adopting it demonstrates to 
stakeholders that the organisation has fulfilled the requirements of the CIC Regulator, particularly when it follows a social accounting and auditing process.

- The existing role of the asset locked body, as a recipient for any assets if the CIC closes down, can be developed further to involve its Board of trustees or directors as an advisory group for the CIC to inform its governance and safeguard against mission drift. This model is similar to that proposed by Mason (2009, p. 230), however in this case the Board is in a separate but closely linked organisation. Their position with a clear stake in, but no legal responsibility for, the CIC should enable the board of the asset locked organisation to act effectively in this role, providing oversight from an external perspective similar to that of the German supervisory board, which overcomes potential conflicts of interest that may arise from having a non-executive group within the organisation (Petrovic 2008). This arrangement enables the CIC board to adopt co-operative working methods with external oversight.

These arrangements would need to be written into the governing document of the CIC to ensure that the asset locked body remains in this role as the CIC develops. Making the asset locked body the recipient of any surplus generated by the CIC gives the latter a clear stake and interest in its success. However, it is not clear from this research if the recommended governance structure would be accepted by infrastructure organisations, social auditors and grant funders in the UK as legitimate. Further research with these bodies would be needed to test this model of governance as legitimate for social enterprise.

\section{References}

AccountAbility (2008) AA1000 Assurance Standard 2008. London: AccountAbility.

Broom A (2005) 'Using qualitative interviews in CAM research: A guide to study design, data collection and data analysis'. Complementary Therapies in Medicine Vol. 13 Iss. 1 pp. 65-73.

Cassell C, Buehring A, Symon G, Johnson P and Bishop V (2005) Qualitative Management Research: A Thematic Analysis of Interviews with Stakeholders in the Field. Swindon: ESRC.

Chapman T, Forbes D and Brown J (2007) “"They have God on their side”: The impact of public sector attitudes on the development of social enterprise'. Social Enterprise Journal Vol. 3 Iss. 1 pp. 78-89.

Checkland P and Holwell S (1998) 'Action Research: Its Nature and Validity'. Systemic Practice and Action Research Vol. 11 No. 1 pp. 9-21.

Cornforth C (2004), 'The Governance of Cooperatives and Mutual Associations: a Paradox Perspective’. Annals of Public and Cooperative Economics Vol. 75 Iss. 1 pp. 11-32.

Cowan C and Todorovic N (2000) 'Spiral Dynamics: the layers of human values in strategy'. Strategy and Leadership Vol. 28 Iss. 1 pp. 4-11.

Crane A and Matten D (2007) Business Ethics (Second Edition). Oxford: Oxford University Press.

Curtis T (2008) 'Finding that grit makes a pearl: A critical re-reading of research into social enterprise’. International Journal of Entrepreneurial Behaviour \& Research Vol. 14 No. 5 pp. 276290.

Dacin P, Dacin M T and Matear M (2010) 'Social Entrepreneurship: Why We Don’t Need a New 
Theory and How We Move Forward From Here'. Academy of Management Perspectives Vol. 24 No. 3 pp. 37-57.

Dart R (2004) 'The Legitimacy of Social Enterprise'. Nonprofit Management \& Leadership Vol. 14 No. 4 pp. 411-424.

Deshpandé R Farley J and Webster F (1993) 'Corporate Culture, Customer Orientation, and Innovativeness in Japanese Firms: A Quadrad Analysis’. The Journal of Marketing Vol. 57 No. 1 pp. 23-37.

DiCicco-Bloom B and Crabtree B (2006) 'The qualitative research interview'. Medical Education Vol. 40 Iss. 4 pp. 314-321.

DiMaggio and Powell (1983) 'The Iron Cage Revisited: Institutional Isomorphism and Collective Rationality in Organizational Fields’. American Sociological Review Vol. 48 No. 2 pp. 147-160.

Drucker P (2007) The Essential Drucker. Oxford: Butterworth-Heinemann.

Fenton N, Passey A and Hems L (1999) ‘Trust, the voluntary sector and civil society'. International Journal of Sociology \& Social Policy Vol. 19 No. 7/8 pp. 21-42.

Flick U (2009) An Introduction to Qualitative Research. London: Sage Publications.

Galera G and Borzaga C (2009) 'Social enterprise: An international overview of its conceptual evolution and legal implementation'. Social Enterprise Journal Vol. 5 No. 3 pp. 210-228.

Kolb A and Kolb D (2005) 'Learning Styles and Learning Spaces: Enhancing Experiential Learning in Higher Education’. Academy of Management Learning \& Education Vol. 4 No. 2, pp. 193-212.

Leadbeater C (1997) The rise of the Social Entrepreneur, London: Demos.

Low C (2006) 'A framework for the governance of social enterprise'. International Journal of Social Economics Vol. 33 No. 5/6 pp. 376-385.

Low C and Chinnock C (2008) 'Governance failure in social enterprise'. Education, Knowledge \& Economy Vol. 2 No. 3 pp. 203-212.

Mason C, Kirkbride J and Bryde D (2007) 'From stakeholders to institutions: the changing face of social enterprise governance theory’. Management Decision Vol. 45 No. 2 pp. 284-301.

Mason C (2009) 'Governance and SEs', in Doherty B, Foster G, Mason C, Meehan J, Meehan K, Rotheroe, $\mathrm{N}$ and Royce M (editors) Management for Social Enterprises. London: Sage.

Meyer J and Rowan B (1977) 'Institutional Organizations: Formal Structure as Myth and Ceremony’. American Journal of Sociology Vol. 83 No. 2 pp. 340-363.

NEF (2008) SORI Guide. London: New Economics Foundation.

Nicholls A (2010) 'The Legitimacy of Social Entrepreneurship: Reflexive Isomorphism in a PreParadigmatic Field’. Entrepreneurship Theory And Practice Vol. 34 Iss. 4 pp. 611-633.

Nicholls J (2007) Why measuring and communicating social value can help social enterprise 
become more competitive. London: Cabinet Office.

Obholzer A (1994) 'Authority, power and leadership', in Obholzer A and Roberts V Z (editors) The Unconscious at Work. Hove: Routledge.

Owen D, Swift T, Humphrey C and Bowerman M (2000) 'The new social audits: accountability, managerial capture or the agenda of social champions?'. The European Accounting Review Vol. 9 Iss. 1 pp. 81-98.

Parkinson J (2003) 'Models of the company and the employment relationship'. British Journal of Industrial Relations Vol. 41 Iss. 3 pp. 481-509.

Patton M (2002) Qualitative Research \& Evaluation Methods (Third Edition). Thousand Oaks: Sage Publications.

Pearce J (2003) Sociał Enterprise in Anytown. London: Calouste Gulbenkian Foundation.

Pearce J and Kay A(2008) Really Telling Accounts. Exeter: Social Audit Network.

Petrovic J (2008) 'Unlocking the role of a board director: a review of the literature'. Management Decision Vol. 46 No. 9 pp. $1373-1392$

Putnam R D (1995) 'Bowling Alone: America's Declining Social Capital'. The Journal of Democracy Vol. 6 Iss. 1 pp. 65-78.

Ridley-Duff R (2009) 'Co-operative social enterprises: company rules, access to finance and management practice’. Social Enterprise JournalVol. 5 No. 1 pp. 50-68.

Roberts V Z (1994A) 'The organisation of work', in Obholzer A and Roberts V Z (editors) The Unconscious at Work. Hove: Routledge.

Roberts V Z (1994B) 'The self assigned impossible task', in Obholzer A and Roberts V Z (editors) The Unconscious at Work. Hove: Routledge.

Rotheroe N and Richards A (2007) 'Social Return on Investment and social enterprise: Transparent accountability for sustainable development’. Social Enterprise Journal Vol. 3 Iss. 1 pp. 31-48.

Seanor P and Meaton J (2008) 'Learning from failure, ambiguity and trust in secial enterprise'. Social Enterprise Journal Vol. 4 No. 1 pp. 24-40.

Seawright J and Gerring J (2008) 'Case Selection Techniques in Case Study Research: A Menu of Qualitative and Quantitative Options’. Political Research Quarterly Vol. 61 No. 2 pp. 294-308.

Spear R Cornforth C and Aiken M (2009) 'The Governance Challenges of Social Enterprises: Evidence From a UK Empirical Study'. Annals of Public and Cooperative Economics Vol. 80 No. 2 pp. 247-273.

Steyaert C and Dey P (2010) 'Nine Verbs to Keep the Social Entrepreneurship Research Agenda “Dangerous”'. Journal of Social Entrepreneurship Vol. 1 No. 2 pp. 231-254.

Stokes J (1994) 'The unconscious at work in groups and teams', in Obholzer A and Roberts V Z (editors) The Unconscious at Work. Hove: Routledge. 
Thompson J and Doherty B (2006) 'The diverse world of social enterprise'. International Journal of Social Economics Vol. 33 No. 5/6 pp. 361-375.

Vartiainen P (2003) 'The Substance of Stakeholder Evaluation: Methodological Discussion'. International Journal of Public Administration Vol. 26 No. 1 pp. 1-18.

Watson T (1995) 'Rhetoric, Discourse and Argument in Organizational Sense Making: A Reflexive Tale’. Organisational Studies Vol. 15 Iss. 5 pp. 805-821.

Yin R (2009) Case Study Research: Design and Methods (Fourth Edition). Thousand Oaks: Sage Publications.

\section{About the authors}

Justin Larner is a social enterprise researcher and practitioner, with a particular interest in governance and stakeholder involvement. He has gained over fifteen years experience working in community-based organisations in the fields of publishing, community architecture, conservation and mental health. Justin has taken a lead in the development of CommEnt as a Community Interest Company with a sustainable loosely co-operative structure that aims to promote and support community enterprise. Justin Larner is the corresponding author and can be contacted at: justin@commentcic.org.uk

Chris Mason is currently lecturing at Swinburne University of Technology, Melbourne, Australia. His previous research focussed on (but is not limited to) social entrepreneurship, governance, and corporate social responsibility.

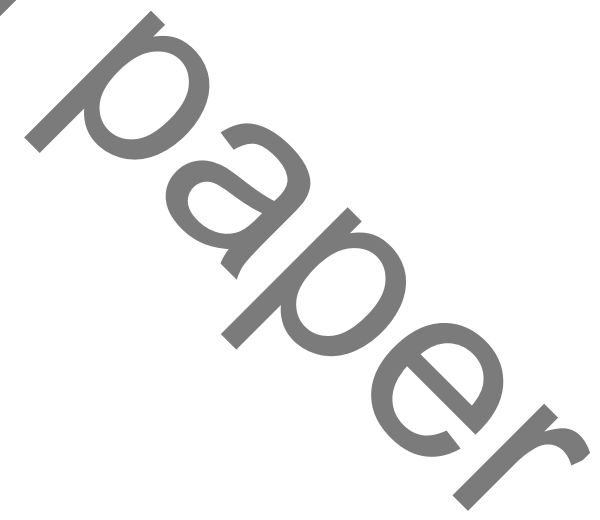

